\title{
Experimental and modeled UV erythemal irradiance under overcast conditions: the role of cloud optical depth
}

\author{
M. Antón ${ }^{1,2}$, L. Alados-Arboledas ${ }^{3,4}$, J. L. Guerrero-Rascado ${ }^{2,3,4}$, M. J. Costa ${ }^{2}$, J. C Chiu ${ }^{5}$, and F. J. Olmo \\ ${ }^{1}$ Departamento de Física, Universidad de Extremadura, Badajoz, Spain \\ ${ }^{2}$ Geophysics Centre of Evora, University of Evora, Evora, Portugal \\ ${ }^{3}$ Departamento de Física Aplicada, Universidad de Granada, Granada, Spain \\ ${ }^{4}$ Centro Andaluz de Medio Ambiente (CEAMA), Universidad de Granada, Granada, Spain \\ ${ }^{5}$ Department of Meteorology, University of Reading, Reading, UK
}

Correspondence to: M. Antón (mananton@unex.es)

Received: 2 July 2012 - Published in Atmos. Chem. Phys. Discuss.: 21 August 2012

Revised: 4 November 2012 - Accepted: 29 November 2012 - Published: 10 December 2012

\begin{abstract}
This paper evaluates the relationship between the cloud modification factor $(\mathrm{CMF})$ in the ultraviolet erythemal range and the cloud optical depth (COD) retrieved from the Aerosol Robotic Network (AERONET) "cloud mode" algorithm under overcast cloudy conditions (confirmed with sky images) at Granada, Spain, mainly for non-precipitating, overcast and relatively homogenous water clouds. Empirical CMF showed a clear exponential dependence on experimental COD values, decreasing approximately from 0.7 for $\mathrm{COD}=10$ to 0.25 for $\mathrm{COD}=50$. In addition, these COD measurements were used as input in the LibRadtran radiative transfer code allowing the simulation of CMF values for the selected overcast cases. The modeled CMF exhibited a dependence on COD similar to the empirical CMF, but modeled values present a strong underestimation with respect to the empirical factors (mean bias of $22 \%$ ). To explain this high bias, an exhaustive comparison between modeled and experimental UV erythemal irradiance (UVER) data was performed. The comparison revealed that the radiative transfer simulations were $8 \%$ higher than the observations for clear-sky conditions. The rest of the bias $(\sim 14 \%)$ may be attributed to the substantial underestimation of modeled UVER with respect to experimental UVER under overcast conditions, although the correlation between both dataset was high $\left(R^{2} \sim 0.93\right)$. A sensitive test showed that the main reason responsible for that underestimation is the experimental AERONET COD used as input in the simulations, which has been retrieved from zenith radiances in the visible range. In this sense, effective COD in the erythemal interval were
\end{abstract}

derived from an iteration procedure based on searching the best match between modeled and experimental UVER values for each selected overcast case. These effective COD values were smaller than AERONET COD data in about $80 \%$ of the overcast cases with a mean relative difference of $22 \%$.

\section{Introduction}

The solar ultraviolet (UV) radiation (100-400 nm) represents a small percentage $(\sim 8 \%)$ of the whole solar spectrum at the top of the atmosphere (Iqbal, 1983). Nevertheless, these high energetic wavelengths are crucial for numerous photochemical processes throughout the atmosphere. Additionally, in appropriate doses, UV radiation plays a key role on several biological reactions like the synthesis of previtamin D3 (Webb and Holick, 1988), while its overexposure may cause detrimental adverse effects for humans, plants, animals and materials (Diffey, 1991, 2004).

UV radiation is attenuated by the complex physical processes of scattering and absorption on its way through the atmosphere, causing a substantial reduction in the UV radiation at the Earth's surface. The atmospheric ozone is the main attenuating factor, and its influence on UV radiation at the surface have been widely studied during the last decades from satellite and ground-based observations at many locations worldwide (World Meteorological Organization (WMO, 2010 and references therein). Nevertheless, the short-term variability of the UV radiation reaching 
the Earth's surface is mainly controlled by changes in the cloud cover which has generally an attenuating effect (up to $80 \%$ ) depending on the cloud type, optical depth, and the distribution across the sky (Alados-Arboledas et al., 2003; Calbó et al., 2005). Additionally, broken-cloud conditions can produce short-term enhancements in UV irradiance (up to $30 \%$ ) over clear-sky conditions compared with the equivalent cloud-free situations (Estupiñan et al., 1996; Sabburg and Calbó, 2009). Cloud effects on solar radiation are commonly expressed by means of the cloud modification factor (CMF), which is the ratio of the measured or simulated irradiance at the surface under cloudy conditions to the calculated cloud-free irradiance under the same atmosphere (Calbó et al., 2005).

Numerous studies can be found in the literature about the evaluation of the CMF in the UV region. Many of them are based on visual observations of cloud amounts and other cloud features reporting CMF values as a function of the parameters observed more often such as cloud cover (typically recorded in oktas, i.e. eighths of sky), cloud type (cumulus, stratocumulus, cirrus, etc.), cloud height (low, middle, or high), and relative cloud-Sun position (basically whether the Sun was obscured by clouds or not) (Paltridge and Barton, 1978; Josefsson, 1986; Ilyas, 1987; Lubin and Frederick, 1991; Bais et al., 1993; Blumthaler et al., 1994; Frederick and Steele, 1995; Thiel et al., 1997; Kuchinke and Nunez, 1999; Alados-Arboledas et al., 2003; Mateos et al., 2010; Esteve et al., 2010). The main two disadvantages of these parameters are the subjectivity of human observations and their low frequency (Josefsson and Landelius, 2000). Thus, in order to avoid these limitations, some studies about the cloudiness effects on CMF in the UV region have been performed using cloud properties (cloud cover, cloud type, and degree of solar disk obstruction) derived from automatic sky cameras (e.g. Schafer et al., 1996; Sabburg and Wong, 2000; Grant and Heisler, 2000). In addition, some authors analyzed the cloud effects on UV irradiance by means of concurrent human or automatic observations of clouds together with measurements of sunshine duration and/or total solar radiation (Estupiñan et al., 1996; Josefsson and Landelius, 2000; Schwander et al., 2002; Trepte and Winkler, 2004; López et al., 2009; Aun et al., 2011).

Most of the works referred in the previous paragraph reported CMF parameterizations through empirical fits to cloud cover values for different cloud types or heights, showing a large variability of CMF values corresponding to the same cloud cover even for a particular location and study period. This behavior is mainly related to the fact that the same cloud cover may present different optical characteristics causing great CMF dispersion (Calbó et al., 2005). Cloud optical depth (COD) or equivalently, column integrated extinction in the cloudy media, is the most fundamental cloud property determining the solar radiation at the Earth's surface. Thus, numerous theoretical studies using radiative transfer codes have evaluated the interaction between
COD and UV radiation (e.g., Frederick and Snell, 1990; Wang and Lenoble, 1996; Mayer et al., 1998; Li et al., 2000; Nichol et al., 2003; Bernhard et al., 2004). However, COD is one of the most poorly measured climate variables, partially because remotely sensing clouds from the surface is challenging (Turner et al., 2007). Consequently, the work that investigated the influence of experimental COD values on UV irradiance is limited (e.g., Krzyscin et al., 2003; Mateos et al., 2011).

In this framework, the present paper is focused on the evaluation of the relationship between COD and UV erythemal irradiance (UVER). For that, simultaneous and independent experimental COD and UVER measurements were recorded between April and November 2007 in Granada (Spain). In addition, modeled UVER values were derived from a radiative transfer code for cloudy conditions using as input, among others, COD measurements. The variability of modeled and empirical CMF values in the erythemal action range related to COD changes is investigated, contributing thus to understand the effects of cloud optical properties on UV radiation.

\section{Instrumentation and data}

All ground-based data were measured at the radiometric station located on the rooftop of the Andalusian Center for Environmental Studies (CEAMA, $37.16^{\circ} \mathrm{N}$, $3.58^{\circ} \mathrm{W}, 680 \mathrm{~m}$ a.s.l.) in Granada (southeastern Spain), a non-industrialized city with a population of about 600000 inhabitants including the metropolitan area.

UVER measurements are recorded by a broadband UV radiometer, model UVB-1, manufactured by Yankee Environmental Systems, Inc. (Massachusetts, US). The erythemal action spectrum (280-400 nm) accounts for the effect of UV radiation on human skin (McKinlay and Diffey, 1987), being adopted as a standard by the Commission Internationale de l'Éclairage (CIE). Measurements were sampled every ten seconds and collected as one minute mean voltages on Campbell CR10X data acquisition systems. Output voltages are converted into UVER values applying the calibration factors derived from the calibration campaign of broadband UV radiometers which took place at the "El Arenosillo" INTA station in Huelva (Spain) in September 2007 (Vilaplana et al., 2009). This campaign included the spectral and angular characterization of the UVB-1 radiometer and their absolute calibration, performed through the outdoor intercomparison with respect to a reference Brewer spectroradiometer (Antón et al., 2011a). The relative uncertainty of the UVER data recorded from broad-band UV radiometers is around $7 \%$ (Hülsen and Gröbner, 2007).

A sun-photometer (CE-318-4, Cimel Electronique France), included in the NASA Aerosol Robotic Network (AERONET) network (Holben et al., 1998), is located near the UVB-1 radiometer. The Cimel sun-photometer is 
designed for retrieving optical and microphysical properties of aerosols from direct Sun and sky measurements at seven wavelengths between 340 and $1020 \mathrm{~nm}$ under cloud-free conditions to avoid cloud-contaminated measurements. In this work, the AERONET level 2 data (the highest quality AERONET data; cloud screening post-calibrated data together with manual inspection) were used (Dubovik and King, 2000). When clouds block the Sun, the sky conditions are not appropriate for retrieving aerosol or cloud properties from the attenuation of the direct solar beam. However, in these situations, the Cimel instrument can be used for monitoring clouds by means of the AERONET "cloud mode" observations. In cloud mode, AERONET sunphotometers point directly up and take 10 zenith radiance measurements at $9 \mathrm{~s}$ intervals for all wavelengths. These measurements are typically available every $15 \mathrm{~min}$, except when sun-photometers operate in a normal "aerosol mode" (i.e., clear-sky or thin cloud conditions) or when wet sensors detect presences of precipitation.

The method for retrieving cloud optical depth from AERONET cloud-mode observations requires the presence of green vegetation in the surrounding area, and uses zenith radiances at 440 and $870 \mathrm{~nm}$ wavelengths, similar to Marshak et al. (2004) and Chiu et al. (2006). At Granada during June-November 2007, surface albedo estimates from the Moderate Resolution Imaging Spectroradiometer (MODIS) Terra/Aqua Combined Collection 5 products (Schaaf et al., 2002) were $0.077 \pm 0.004$ and $0.262 \pm 0.016$ at 440 and $870 \mathrm{~nm}$ wavelengths, respectively, with normalized difference vegetation index (NDVI) values larger than 0.3. This spectral contrast in surface albedo is comparable with the value observed at the ARM Oklahoma site (Chiu et al., 2010), indicating a sufficient presence of green vegetated areas for our retrieval purposes.

AERONET cloud-mode retrievals represent 1.5 min cloud optical depth, averaged from instantaneous cloud optical depths that are estimated by comparing radiance measurements taken every $9 \mathrm{~s}$ at 440 and $870 \mathrm{~nm}$ wavelengths against pre-calculated lookup tables. For overcast cases, Chiu et al. (2010) showed that cloud-mode optical depths agreed to within $15 \%$ of those from a flux method that was similar to Min and Harrison (1996). Further descriptions and evaluations of the cloud-mode retrieval method can be found in Chiu et al. (2010).

An All-Sky Imager was used to obtain images of the whole sky dome in daytime during the study period (Cazorla, 2008a). This instrument is a custom adaptation of a CCD camera for scientific used with a fish-eye lens pointing at zenith and has been previously used for cloud cover characterization and retrieval of atmospheric aerosol load $(\mathrm{Ca}-$ zorla et al., 2008b, 2009). All-Sky Imager was used to select only overcast situations for this study.

\section{Methodology}

\subsection{Empirical CMF}

The empirical CMF in the UV erythemal range is evaluated as:

$\mathrm{CMF}_{\text {emp }}=\frac{\text { UVER }_{\text {exp }}^{\text {cloudy }}}{\text { UVER }_{\mathrm{emp}}^{\text {clear }}}$,

where $\mathrm{UVER}_{\exp }^{\text {cloudy }}$ represents the experimental erythemal data recorded under cloudy (overcast) conditions in Granada and UVER clear corresponds to the erythemal data for the same solar zenith angle (SZA) and atmospheric conditions but for clear-sky conditions (cloud-free and low turbidity conditions). These $\mathrm{UVER}_{\mathrm{emp}}^{\text {clear }}$ data are estimated from the following empirical expression proposed by Madronich (2007):

$\operatorname{UVER}_{\mathrm{emp}}^{\mathrm{clear}}=a\left(\mu_{0}\right)^{b}\left(\frac{\mathrm{TOC}}{300}\right)^{c}$,

where $\mu_{0}$ is the cosine of SZA and TOC is the total ozone column in Dobson Units (DU). Antón et al. (2011b) calculated the coefficients ( $a, b$ and $c$ ) for Granada from a regression analysis using experimental UVER data measured under clear sky conditions from January 2006 to December 2007. All-Sky Imager was used to select cloud-free cases (oktas smaller than 1) while the Cimel sun-photometer guaranteed simultaneous clear aerosol conditions (aerosol optical depth (AOD) at 380 and $440 \mathrm{~nm}$ smaller than 0.1). Thus, it was implicitly assumed that the atmospheric aerosol during clear sky conditions over Granada is the natural background (Lyamani et al., 2010). Antón et al. (2011b) also validated the empirical clear-sky model given by expression 2 using data recorded during a period not previously used for calculating the fitting coefficients (January-December 2008). The validation results reported an excellent agreement between the experimental and empirical data for clear-sky cases with relative differences smaller than $2.5 \%$.

\subsection{Modeled CMF}

The use of a radiative transfer code allows for the evaluation of the CMF during the study period whenever the model is properly fed:

$\mathrm{CMF}_{\text {mod }}=\frac{\mathrm{UVER}_{\text {mod }}^{\text {cloudy }}}{\mathrm{UVER}_{\text {mod }}^{\text {clear }}}$

The modeled UVER mod $_{\text {cloudy }}$ and UVER mod $_{\text {clear }}$ values were derived from the LibRadtran software package whose main tool is the LibRadtran/UVSPEC model, developed by Mayer and Kylling (2005). The pSeudospherical DIScrete Ordinate Radiative Transfer (SDISORT) method numerically solves the radiative-transfer equation in a vertically non-homogeneous 
plane-parallel atmosphere, running in 16 stream mode. We implemented the UVSPEC model using standard profiles from the standard atmosphere midlatitude summer (afglms), and midlatitude winter (afglmw), which comprise 50 levels between 0 and $120 \mathrm{~km}$ (Anderson et al., 1986). The model uses as input the daily TOC data provided by the Ozone Monitoring Instrument (OMI) (Levelt et al., 2006). Additionally, a fixed surface UV albedo of 0.035 was assumed in all simulations. This value was derived for the study site from the UV albedo climatology over Europe, within the European Union's action COST-726, "Long term changes and climatology of UV radiation over Europe" (Litynska et al., 2010).

For the simulation of the UVER mod $_{\text {clody }}$ data, we assumed a vertically homogeneous cloud layer inserted between 2 and $3 \mathrm{~km}$ a.s.l. (1320-2320 $\mathrm{m}$ above ground) with an effective droplet radius of $10 \mu \mathrm{m}$ which is an appropriate value for liquid water clouds in midlatitudes (Min and Harrison, 1996; Kylling et al., 2005; Binyamin et al., 2010; Mateos et al., 2011). To characterize the optical properties of clouds, the experimental COD derived from AERONET "cloud mode" observations are used as input in the UVSPEC model. Additionally, aerosols were also taken into account in these simulations. Thus, the spring-summer and fall-winter aerosol profiles given by Shettle (1989) were used. We chose an urban aerosol type and the impact of the aerosol loading in the boundary was expressed by means of daily averages of the Angstrom's coefficients ( $\alpha$ and $\beta$ ) retrieved from the Cimel sun-photometer. In addition, the daily average values of single scattering albedo and the asymmetry factor retrieved from this instrument at $440 \mathrm{~nm}$ were also included in the simulations. When persistent cloudy conditions were present throughout a day, and no Cimel measurements were available, an interpolation between the closest daily averages values was performed.

$\mathrm{UVER}_{\text {mod }}^{\text {clear }}$ values were modeled assuming cloud-free conditions. In addition, the atmospheric aerosol for these simulations is the natural background. For that, we set to constant values of 1.20 and 0.03 for $\alpha$ and $\beta$, and 0.88 and 0.68 for the single scattering albedo and the asymmetry factor, respectively. These values are set based on averages of the Cimel sun-photometer measurements under clear conditions (AOD at 380 and $440 \mathrm{~nm}$ smaller than 0.1 ) during the period January-December 2007 at Granada.

\section{Results and discussion}

Figure 1 exhibits the empirical CMF values as a function of the 1.5-min average AERONET COD data recorded at Granada under overcast situations. The empirical CMF values shown in this plot were obtained from the average of the experimental UVER data measured within $\pm 1 \mathrm{~min}$ (three 1-min UVER measurements) around each Cimel sunphotometer measurement. Additionally, to select the overcast conditions, the information about cloud cover derived

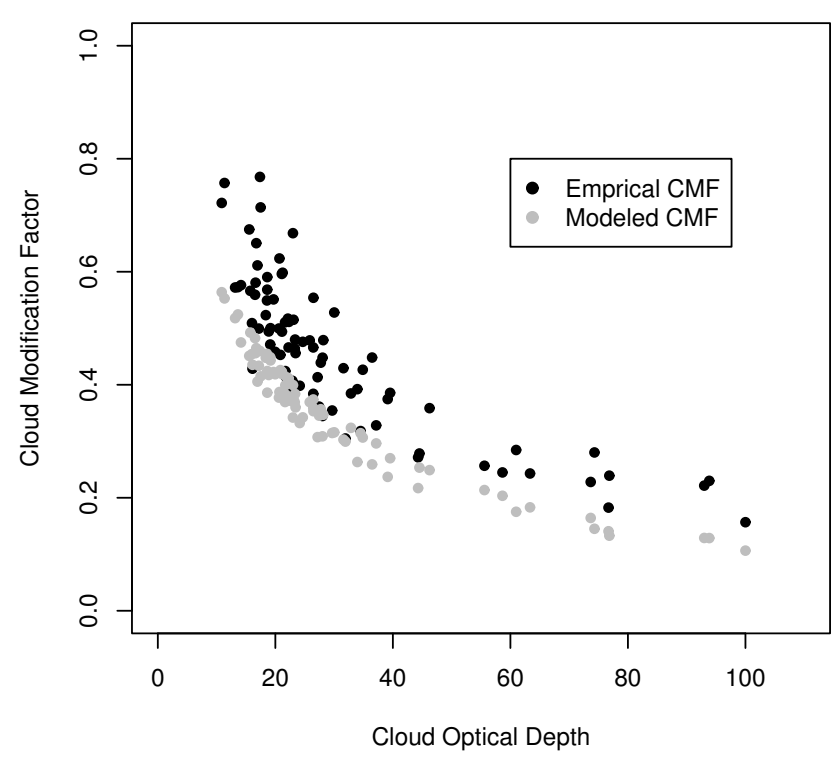

Fig. 1. The empirical and modeled CMF as a function of the AERONET COD data recorded at Granada under overcast situations.

from the All-Sky Imager is employed in this work. Thus, only those pairs of values CMF-COD recorded under a cloud cover of 8 oktas and a sky-cover percentage of opaque clouds larger than $90 \%$ are shown in the plot (95 overcast cloud cases). In addition, since cloud-mode retrievals are based on water cloud assumption, ice cloud cases need to be minimized to warrant a meaning intercomparison in Fig. 1. Unfortunately, information on cloud boundaries from groundbased active instruments (lidar) was not available during the time period of interest. To estimate the possibility of ice cloud contamination in our intercomparison, we checked cloud phase retrievals from MODIS cloud product Level 2 data (collection 5), focusing on overpasses that have time differences less than $30 \mathrm{~min}$ from cloud-mode measurements. As a result, $85 \%$ of MODIS retrievals correspond to liquid phase.

It can be seen from Fig. 1 that CMF decreases approximately exponentially as COD increases, making evident that surface UVER is very sensitive to this atmospheric variable. Thus, for fairly thick clouds of optical thickness of 10 (clouds through which the Sun's outline generally cannot be seen from the surface) UVER reaching the Earth's surface is about $70 \%$ the amount of its clear-sky value. This percentage diminishes quickly as cloud increases its optical thickness until a value of about $25 \%$ for COD around 50 . From this value of optical thickness, the UVER transmission decreases slowly due to the already high contribution to radiation reflected to space.

Figure 1 also shows the modeled CMF values (Eq. 3) which present a reduced variability for each COD value while it is obvious the large dispersion of empirical CMF 
values corresponding to the same COD value. For instance, for a fixed COD of 20, the empirical CMF values range between 0.4 and 0.7 while the modeled CMF values are around 0.4 with a very slight variability mainly related to the use of a homogenous cloud layer of fixed characteristics. This result suggests that one-dimensional radiative transfer theory based on a homogenous cloud layer cannot completely explain the actual variability of surface UVER associated with changes on the complicated inhomogeneous structure of cloud field. Additionally, Fig. 1 also exhibits that modeled CMF values clearly underestimate the empirical data, being the mean value ( \pm 1 standard deviation) of relative differences $\left(\mathrm{CMF}^{\mathrm{mod}}-\mathrm{CMF}^{\mathrm{emp}} / \mathrm{CMF}^{\mathrm{emp}}\right)$ of $(-22 \pm 13) \%$. From Eqs. (1) and (3), this substantial bias can be associated with two possible causes: $\mathrm{UVER}_{\text {mod }}^{\text {cloud }}$ values are smaller than $\mathrm{UVER}_{\mathrm{exp}}^{\text {cloudy }}$ and/or $\mathrm{UVER}_{\text {mod }}^{\text {clear }}$ values are larger than $\mathrm{UVER}_{\mathrm{emp}}^{\text {clear }}$.

To investigate these two possible causes, Fig. 2 displays two plots with the correlation of UVER values for cloudy and clear-sky conditions. Thus, the empirical UVER against modeled values for the ideal clear-sky conditions are shown in Fig. 2 (top). It can be seen that although the correlation is excellent $\left(R^{2} \sim 0.99\right)$ and the spread is very small (RMSE $\sim 3.9 \%$ ), the modeled UVER data are notably higher (mean bias of $8.7 \%$ ) than the empirical values, which can explain a substantial part of the large bias found in the modeled CMF (i.e., Fig. 1).

To understand the sources of the $8.7 \%$ bias, we evaluated modeled and empirical values against experimental data for clear-sky conditions, although one should bear in mind that experimental data have a relative uncertainty of $7 \%$ (Hülsen and Gröbner, 2007). By selecting clear-sky cases that have oktas smaller than 1 and AOD values smaller than 0.1 at 380 and $440 \mathrm{~nm}$, the resulting 549 cases show that the mean relative differences between modeled and experimental data was $(+8 \pm 5) \%$, which agrees with reported biases (smaller than $10 \%$ for clear-sky conditions) in numerous inter-comparisons using the LibRadtran code (e.g., Mayer et al., 1997; Kylling et al., 1998; de Backer et al., 2001). However, since this bias is comparable with measurement uncertainty, errors from radiative transfer calculations could be negligible, indicating that a reduction in measurement uncertainty will potentially help refine the empirical relationship and consequently lower the bias for clear-sky conditions.

On the other hand, the relationship between experimental and modeled UVER data under cloudy conditions is shown in Fig. 2 (bottom). The correlation is reasonably good $\left(R^{2} \sim 0.93\right)$, but it is obvious that the model clearly underestimates the measured data with a high mean bias of $14.5 \%$. Therefore, most of the bias found for modeled CMF $(\sim 22 \%)$ is associated with the overestimation of the cloud effects on surface UVER values by the radiative transfer code. The main cause of this overestimation may be related to the cloud parameters used as input in the simulations. Thus, in order
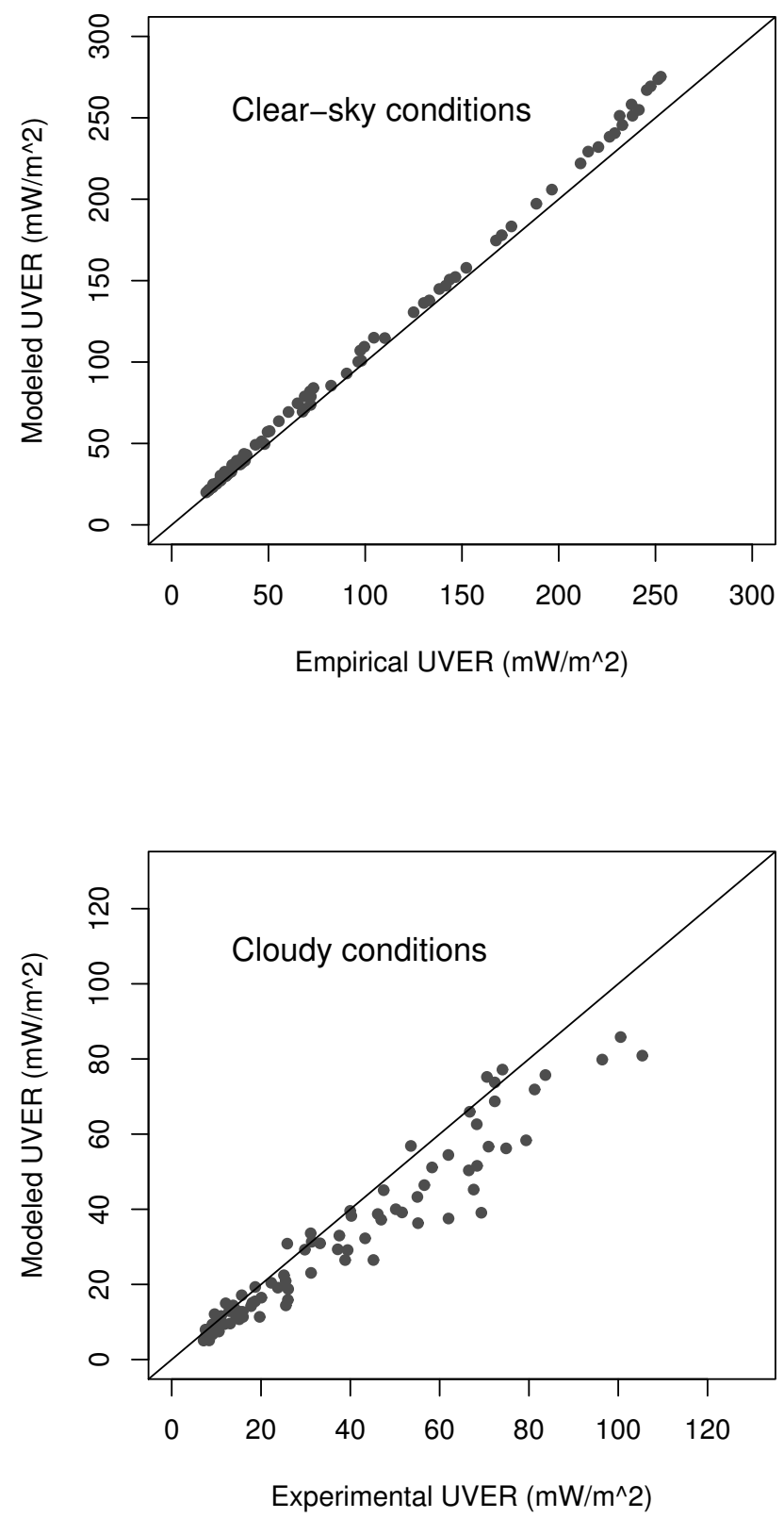

Fig. 2. Top: the empirical UVER against modeled values for the ideal clear-sky conditions corresponding to actual cloudy cases. Bottom: correlation between experimental and modeled UVER data under cloudy conditions. The solid black line is the zero bias line, unit slope.

to analyze the influence of these parameters on the modeled UVER, we have performed a sensitive test with several scenarios for each cloudy case:

(a) Geometrical depth of the cloud layer is evaluated by means of four different thicknesses: $1 \mathrm{~km}$ (Scenario A.1), $2 \mathrm{~km}$ (Scenario A.2), $3 \mathrm{~km}$ (Scenario A.3) and $4 \mathrm{~km}$ (Scenario A.4). The height of the cloud bottom was set to 
$2 \mathrm{~km}$ a.s.l. and the effective radius of cloud droplets was set to $10 \mu \mathrm{m}$ for all four cases.

(b) Cloud altitude is studied positioning the $1 \mathrm{~km}$ thick cloud layer at different heights with a fixed effective radius of $10 \mu \mathrm{m}$ : 1-2 km (Scenario B.1), 2-3 km (Scenario B.2), 3-4 km (Scenario B.3), 4-5 km (Scenario B.4) and 5$6 \mathrm{~km}$ (Scenario B.5).

(c) The effective radius is analyzed setting values of $5, \mu \mathrm{m}$ (Scenario C.1), $7.5 \mu \mathrm{m}$ (Scenario C.2), $10 \mu \mathrm{m}$ (Scenario C.3), $12.5 \mu \mathrm{m}$ (Scenario C.4) and $15 \mu \mathrm{m}$ (Scenario C.5) for the $1 \mathrm{~km}$ thick cloud located between 2 and $3 \mathrm{~km}$.

Scenarios A.1, B. 2 and C. 3 correspond to the same cloudy situation (cloud inserted between 2 and $3 \mathrm{~km}$ a.s.l. with an effective droplet radius of $10 \mu \mathrm{m}$ ), which has been used as fixed cloud situation, reference, in all simulations of this work. Thus, Fig. 3 shows three plots with the ratio of each scenario to the reference as a function of the COD used as input in the simulations. The ratios for the scenario A (variation of geometrical thickness) are displayed in Fig. 3 (top). It can be seen that surface UVER for geometrically-thick clouds are smaller than for geometrically-thin clouds with identical optical thickness. This result could be attributed to an amplification of UV absorption by the tropospheric ozone located within clouds due to the enhancement in the optical path by scattering processes, as was evidenced and explained by several authors (Frederick and Lubin, 1988; Wang and Lenoble, 1996; Mayer et al., 1998). The described amplification effect depends on the amount of ozone inside the clouds, and consequently it depends on their geometrical thickness, being stronger for clouds with large vertical extent than for geometrically-thin clouds. Additionally, the ratios also show an appreciable dependence on the optical thickness, decreasing with increasing COD, which indicate that the amplification effect is also closely associated with the variation of the optical path inside the clouds. Nevertheless, all relative differences with respect to the reference scenario are smaller than $5 \%$ for COD values below 40 , and only increase to values around $15 \%$ for the highest COD. On the other hand, Fig. 3 (middle) exhibits that ratios for scenario B are almost insensitive to the variation of the cloud base height. The relative differences of the modeled UVER with respect to those derived from the reference scenario are smaller than $5 \%$ for the whole range of COD. It is evident that the cloud scattering is dominant to molecules and aerosols scattering whatever the cloud altitude is. Finally, Fig. 3 (bottom) shows that larger cloud droplet radius (scenario C) increases the forward cloud scattering and thus the surface UVER values, but relative differences smaller than $3 \%$ for all COD values indicate that the droplet size variability does not have crucial influence on surface UVER.

To conclude, when COD is added as input to the model, changes on effective droplet radius, geometrical thickness and altitude of the clouds introduce systematic errors in
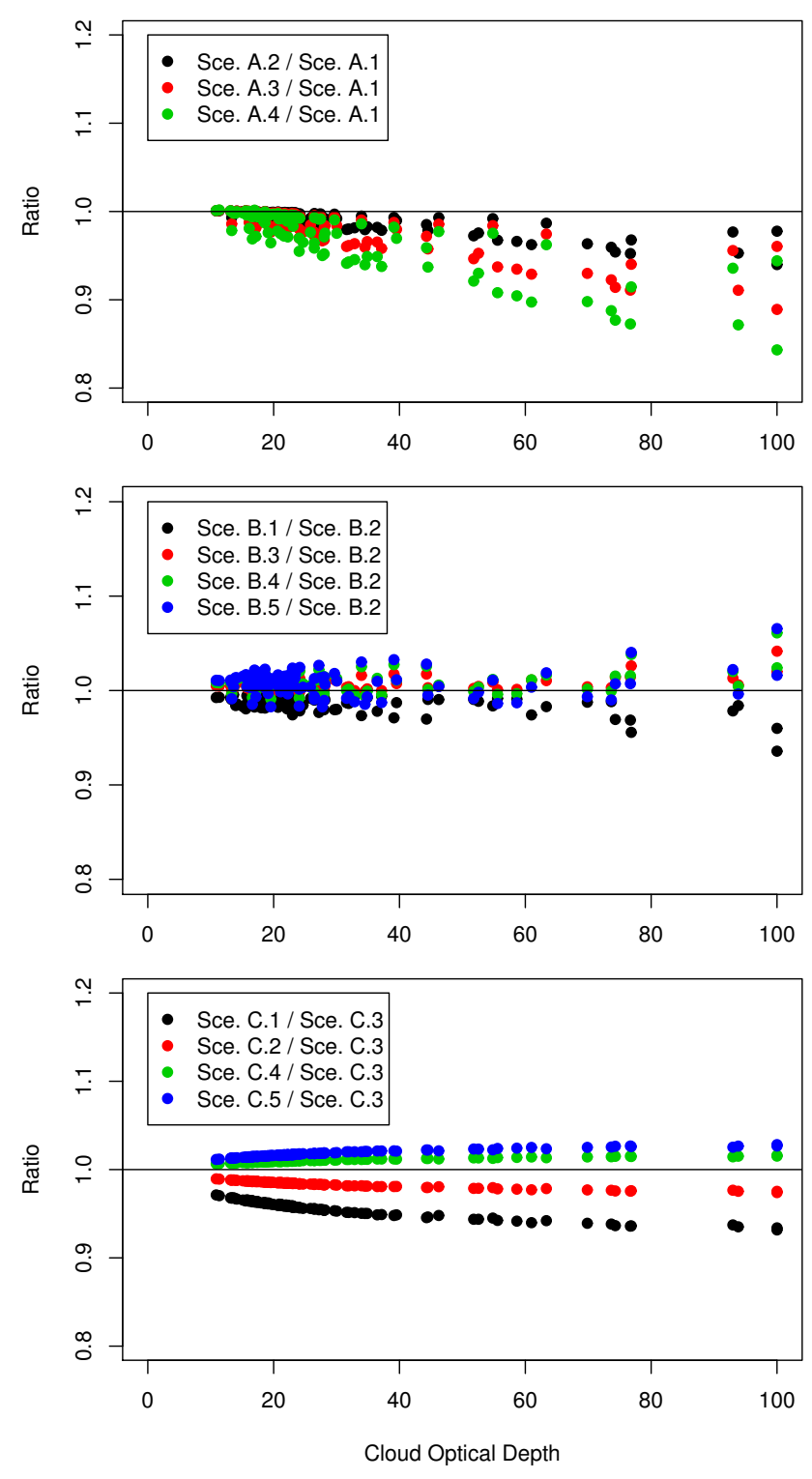

Fig. 3. Top: the ratio of scenario A (variation of top-base cloud distance) to the reference scenario (A.1) as a function of the COD. Middle: the ratio of scenario $\mathrm{B}$ (variation of the cloud base height) to the reference (B.2) as a function of the COD. Bottom: the ratio of scenario $\mathrm{C}$ (variation of cloud droplet radius) to the reference (C.3) as a function of the COD.

simulating cloudy UVER data and, consistently, in deriving CMF values. However, these errors are rather small compared with those resulting from variations in COD (see Fig. 1). Only the variation of geometrical thickness for large COD values could involve some uncertainty in the simulations. These results are in agreement with the conclusions reported in Forster (1995) and Wang and Lenoble (1996).

From the above results, the underestimation of modeled UVER with respect to the experimental UVER in Fig. 2 (bottom) may be mainly related to the AERONET COD data 
used as input in the model. Thus, while for each UVER simulation the COD is assumed constant and thus represents a hemispherical property of clouds, AERONET cloud-mode retrievals mainly represent overhead cloud properties in low cloud situations. If clouds are homogeneous, this intrinsic difference in COD representativeness introduces no discrepancy in inter-comparison results. In reality, clouds are heterogeneous; therefore, cloud-mode retrievals are generally larger than those from hemispherical radiation measurements due to their concave relationship with cloud optical depth (as shown in Chiu et al., 2006).

To check the previous assumption, the effective optical thickness in the UV erythemal range has been derived from an iteration procedure proposed by Leontyeva and Stammes (1994) using modeled and experimental UVER values. Thus, for each cloudy case, successive modeled UVER values have been simulated from UVSPEC varying the COD inputs with a step of 0.5 (cloud layer is fixed between 2 and $3 \mathrm{~km}$ with an effective droplet radius of $10 \mu \mathrm{m}$ ) and with real aerosol information also included in the simulations. The iterative process is finished when for a given COD value the relative difference between the modeled and experimental UVER values is smaller than $1 \%$. The model COD is the effective optical thickness resulting from the iteration. Therefore, the term "effective" indicates the COD value that used as input in the code best agrees with experimental UVER data. Figure 4 shows the relationship between AERONET COD and the effective values in the erythemal range derived from the method described previously. The correlation between both data sets is fairly good $\left(R^{2} \sim 0.8\right)$, with a significantly large spread (RMSE $\sim 39 \%$ ). Additionally, it can be seen that in most cases the effective COD values are lower than the AERONET data. This underestimation occurs in around $80 \%$ of all cloudy cases. The mean value of the relative differences $\left(\mathrm{COD}^{\mathrm{EFEC}}-\mathrm{COD}^{\mathrm{AERO}} / \mathrm{COD}^{\mathrm{AERO}}\right)$ is $-22 \%$. These results confirm the assumption that COD values in the erythemal range are smaller than AERONET COD data which has been obtained from two wavelengths in the visible range. Therefore, a substantial part of the biases shown in Figs. 1 and 2 (bottom) for the modeled values may be associated with this issue.

\section{Conclusions}

The analysis of cloud optical effects in the erythemal range by means of COD data retrieved from AERONET "cloud mode" have provided several relevant conclusions. For cases with non-precipitating, overcast and relatively homogeneous water clouds, empirical CMF values have shown a clear exponential dependence with respect to experimental COD data. In general, CMF values decrease from 0.7 to 0.25 when cloud optical depth increases from 10 to 50 .

AERONET COD data were also used as input in radiative transfer simulations to obtain modeled CMF, which ex-

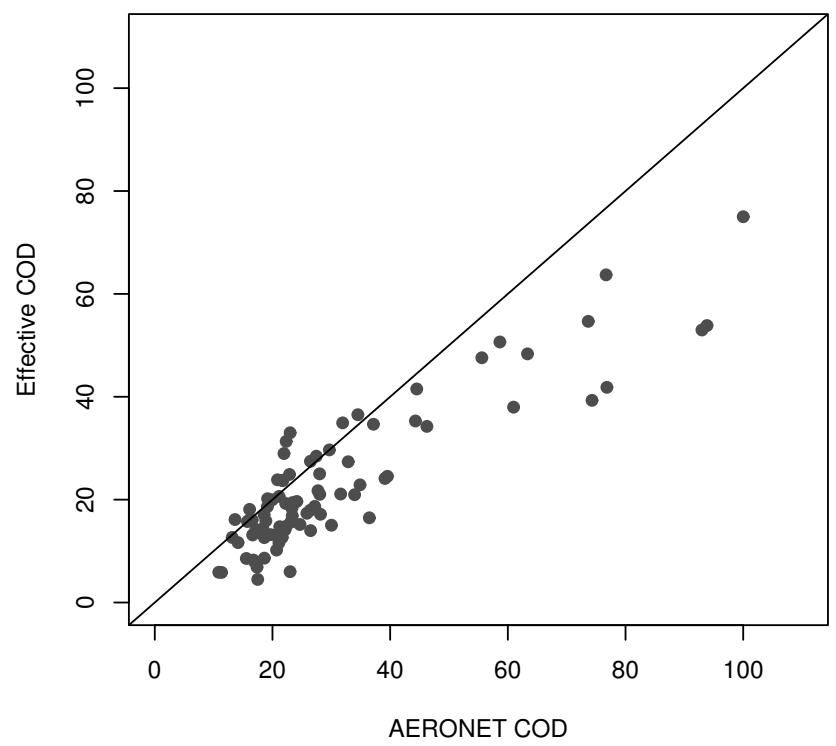

Fig. 4. Correlation between AERONET COD and effective COD values in the erythemal range. The solid black line is the zero bias line, unit slope.

hibited a large underestimation of empirical values ( $22 \%)$. A substantial part of this bias may be due to that the radiative transfer simulations were $8 \%$ higher than the observations for clear-sky conditions. This result highlights that the use of an empirical model for the estimation of ideal cloudless conditions clearly reduce the uncertainty of CMF values. The rest of the bias $(\sim 14 \%)$ was associated with the underestimation of surface UVER under cloudy cases by the radiative transfer model. The detailed analyses of this large underestimation reported relevant results. Thus, when experimental COD are included as input in the code, variations of the other cloud parameters (geometrical thickness, height of the top or bottom, effective droplet radius) present a reduced influence on UVER simulations. Therefore, the main reason responsible for the significant differences between modeled and experimental UVER data under cloudy conditions was the AERONET COD used in the model.

For around $80 \%$ of the overcast cases, an iteration method showed that the effective COD values (those that find the best match between modeled and experimental UVER values) are smaller than AERONET COD data. This result might be partially explained by the use of zenith radiances to retrieve the AERONET COD data (representing the cloud overhead), while the effective COD is derived from UVER fluxes (representing the entire hemisphere).

In conclusion, the inclusion of AERONET COD as input in 1-D radiative transfer codes could produce additional uncertainties in the modeled hemispherical UV fluxes under cloudy conditions. Nevertheless, the combination of the experimental UV data and the AERONET "cloud mode" observations is very promising. 
Acknowledgements. Manuel Antón thanks Ministerio de Ciencia e Innovación and Fondo Social Europeo for the award of a postdoctoral grant (Ramon y Cajal). C. Chiu was supported by the Office of Science (BER, US Department of Energy, Interagency agreement DE-SC0006001) as part of the ASR program. We also thank the AERONET team for providing instrument calibration and data processing. MODIS data were obtained from the Level 1 and Atmosphere Archive and Distribution System (LAADS, http://ladsweb.nascom.nasa.gov). This work was partially supported by the Andalusian Regional Government through projects P08-RNM-3568 and P10-RNM-6299, the the Ministerio de Ciencia e Innovación through projects CGL2008-05939-C03-03/CLI, CGL2010-18782, CGL-2011-2992-1-C02-01 and CSD200700067, and by European Union through ACTRIS project (EU INFRA-2010-1.1.16-262254). This work is co-financed through FEDER (Programa Operacional Factores de Competitividade COMPETE) and National funding through FCT - Fundação para a Ciência e a Tecnologia in the framework of project FCOMP-010124-FEDER-009303 (PTDC/CTE-ATM/102142/2008).

Edited by: B. Mayer

\section{References}

Alados-Arboledas, L., Alados, I., Foyo-Moreno, I., Olmo, F. J., and Alcántara, A.: The influence of clouds on surface UV erythemal irradiance, Atmos. Res., 66, 273-290, 2003.

Anderson, G., Clough, S., Kneizys, F., Chetwynd, J., and Shettle, E.: AFGL atmospheric constituent profiles $(0-120 \mathrm{~km})$, Tech. Rep. AFGL-TR-86-0110, Air Force Geophys. Lab., Hanscom Air Force Base, Bedford, Mass, 1986.

Antón, M., Gil, J. E., Cazorla, A., Fernández-Gálvez, J., Vilaplana, J. M., Olmo, F. J., and Alados-Arboledas, L.: Influence of the calibration on experimental UV index at a midlatitude site, Granada (Spain), Atmos. Meas. Tech., 4, 499-507, doi:10.5194/amt-4499-2011, 2011a.

Antón, M., Gil, J. E., Fernández-Gálvez, J., Lyamani, H., Valenzuela, A., Foyo-Moreno, I., Olmo, F. J., and Alados-Arboledas, L.: Evaluation of the aerosol forcing efficiency in the UV erythemal range at Granada (Spain), J. Geophys. Res., 116, D20214, doi:10.1029/2011JD016112, $2011 \mathrm{~b}$.

Aun, M., Eerme, K., Ansko, I., Veismann, U., and Lätt, S.: Modification of spectral ultraviolet doses by different types of overcast cloudiness and atmospheric aerosol, Photochem. Photobiol., 87, 461-469, 2011.

Bais, A. F., Zerefos, C. S., Meleti, C., Ziomas, I. C., and Tourpali, K.: Spectral measurements of solar UVB radiation and its relations to total ozone, $\mathrm{SO}_{2}$ and clouds, J. Geophys. Res., 98, 51995204, 1993.

Bernhard, G., Booth, C. R., and Ehramjian, J. C.: Version 2 data of the National Science Foundation's Ultraviolet Radiation Monitoring Network: South Pole, J. Geophys. Res., 109, D21207, doi:10.1029/2004JD004937, 2004.

Binyamin, J., Davies, J., and McArthur, B.: UV-B cloud optical properties for Canada, Int. J. Climatol., 30, 1246-1255, 2010.

Blumthaler, M., Ambach, W., and Salzberg, M.: Effects of cloudiness on global and diffuse UV irradiance in a high mountain area, Theor. Appl. Climatol., 50, 23-30, 1994.
Calbó, J., Pagés, D., and González, J.: Empirical studies of cloud effects on UV radiation: A review, Rev. Geophys., 43, RG2002, doi:10.1029/2004RG000155, 2005.

Cazorla, A., Olmo, F. J., and Alados-Arboledas, L.: Development of a sky imager for cloud cover assessment, J. Opt. Soc. Am. A., 25, 29-39, doi:10.1364/JOSAA.25.000029, 2008a.

Cazorla, A., Olmo, F. J., and Alados-Arboledas, L.: Using a sky imager for aerosol characterization, Atmos. Environ., 42, 27392745, doi:10.1016/j.atmosenv.2007.06.016, 2008b.

Cazorla, A., Shields, J. E., Karr, M. E., Olmo, F. J., Burden, A., and Alados-Arboledas, L.: Technical Note: Determination of aerosol optical properties by a calibrated sky imager, Atmos. Chem. Phys., 9, 6417-6427, doi:10.5194/acp-9-6417-2009, 2009.

Chiu, J. C., Marshak, A., Knyazikhin, Y., Wiscombe, W. J., Barker, H. W., Barnard, J. C., and Luo, Y.: Remote sensing of cloud properties using ground-based measurements of zenith radiance, J. Geophys. Res., 111, D16201, doi:10.1029/2005JD006843, 2006.

Chiu, J. C., Huang, C. H., Marshak, A., Slutsker, I., Giles, D. M., Holben, B.N., Knyazikhin, Y., and Wiscombe, W. J.: Cloud optical depth retrievals from the Aerosol Robotic Network (AERONET) cloud mode observations, J. Geophys. Res., 115, D14202, doi:10.1029/2009JD013121, 2010.

de Backer, H., Koepke, P., Bais, A., de Cabo, X., Frei, T., Gillotay, D., Haite, C., Heikkilä, A., Kazantzidis, A., Koskela, T., Kyrö, E., Lapeta, B., Lorente, J., Masson, K., Mayer, B., Plets, H., Redondas, A., Renaud, A., Schauberger, G., Schmalwieser, A., Schwander, H., and Vanicek, K.: Comparison of measured and modelled uv indices for the assessment of health risks, Meteorol. Appl., 8, 267-277, 2001.

Diffey, B.: Solar ultraviolet radiation effects on biological systems, Phys. Med. Biol., 36, 299-328, 1991.

Diffey, B.: Climate change, ozone depletion and the impact on ultraviolet exposure of human skin, Phys. Med. Biol., 49, R1-R11, 2004.

Dubovik, O. and King, M. D.: A flexible inversion algorithm for retrieval of aerosol optical properties from Sun and sky radiance measurements, J. Geophys. Res., 105, 20673-20696, doi:10.1029/2000JD900282, 2000.

Esteve, A. R., Marin, M. J., Tena, F., Utrillas, M. P., and MartínezLozano, J. A.: Influence of cloudiness over the values of erythemal radiation in Valencia, Spain, Int. J. Climatol., 30, 127-136, doi:10.1002/joc.1883, 2010.

Estupiñan, J. G., Raman, S., Grescenti, G. H., Streicher, J. J., and Barnard, W. F.: Effects of clouds and haze on UV-B radiation, J. Geophys. Res., 101, 16807-16816, 1996.

Forster, P. M. de F.: Modeling ultraviolet radiation at the Earth's surface. Part I: The sensitivity of ultraviolet irradiances to atmospheric changes, J. Appl. Meteorol., 34, 2412-2425, 1995.

Frederick, J. E. and Snell, H. E.: Tropospheric influence on solar ultraviolet radiation: The role of clouds, J. Climatol., 3, 373-381, 1990.

Frederick, J. E. and Steele, H. D.: The transmission of sunlight through cloudy skies: An analysis based on standard meteorological information, J. Appl. Meteorol., 34, 2755-2761, 1995.

Grant, R. H. and Heisler, G. M.: Estimation of ultraviolet-B irradiance under variable cloud conditions, J. Appl. Meteorol, 39, 904-916, 2000.

Holben, B. N., Eck, T. F., Slutsker, I., Tanre, D., Buis, J. P., Setzer, A., Vermote, E., Reagan, J. A., Kaufman, Y. J., Nakajima, T., 
Lavenu, F., Jankowiak, I., and Smirnov, A.: AERONET - A federated instrument network and data archive for aerosol characterization, Remote Sens. Environ., 66, 1-16, doi:10.1016/S00344257(98)00031-5, 1998

Hülsen, G. and Gröbner, J.: Characterization and calibration of ultraviolet broadband radiometers measuring erythemally weighted irradiance, Appl. Optics, 46, 5877-5886, 2007.

Ilyas, M.: Effect of cloudiness on solar ultraviolet radiation reaching the surface, Atmos. Environ., 21, 1483-1484, 1987.

Iqbal, M.: Introduction to Solar Radiation, Acad. Press, Toronto, Canada, 1983.

Josefsson, W.: Solar ultraviolet radiation in Sweden, SMHI Rep. Meteorol. Climatol. 53, 71 pp., Swed. Meteorol. And Hydrol. Inst., Norrköping, Sweden, 1986.

Josefsson, W. and Landelius, T.: Effect of clouds on UV irradiance: As estimated from cloud amount, cloud type, precipitation, global radiation and sunshine duration, J. Geophys. Res., 105, 4927-4935, 2000.

Krzyscin, J. W., Jaroslawski, J., and Sobolewski, P. S.: Effects of clouds on the surface erythemal UV-B irradiance at northern midlatitudes: Estimation from the observations taken at Belsk, Poland (1999-2001), J. Atmos. Sol.-Terr. Phy., 65, 457-467, 2003.

Kuchinke, C. and Nunez, M.: Cloud transmission estimates of UV-B erythemal irradiance, Theor. Appl. Climatol., 63, 149-161, 1999.

Kylling, A., Bais, A. F., Blumthaler, M., Schreder, J., Zerefos, C. S., and Kosmidis, E.: Effect of aerosols on solar UV irradiances during the photochemical activity and solar ultraviolet radiation campaign, J. Geophys. Res., 103, 26051-26060, 1998.

Kylling, A., Webb, A. R., Kift, R., Gobbi, G. P., Ammannato, L., Barnaba, F., Bais, A., Kazadzis, S., Wendisch, M., Jäkel, E., Schmidt, S., Kniffka, A., Thiel, S., Junkermann, W., Blumthaler, M., Silbernagl, R., Schallhart, B., Schmitt, R., Kjeldstad, B., Thorseth, T. M., Scheirer, R., and Mayer, B.: Spectral actinic flux in the lower troposphere: measurement and 1-D simulations for cloudless, broken cloud and overcast situations, Atmos. Chem. Phys., 5, 1975-1997, doi:10.5194/acp-5-1975-2005, 2005.

Leontyeva, E. and Stammes, K.: Estimations of cloud optical thickness from ground-based measurements of incoming solar radiation in the Artic, J. Climatol., 7, 566-578, 1994.

Levelt, P. F., Hilsenrath, E., Leppelmeier, G. W., Van den Oord, G. H. J., Bhartia, P. K., Tamminen, J., De Haan, J. F., and Veefkind, J. P.: The ozone monitoring instrument, IEEE T. Geosci. Remote, 44, 1093-1101, 2006.

Li, Z., Wang, P., and Cihlar, J.: A simple and efficient method for retrieving surface UV radiation dose rate from satellite, J. Geohys. Res., 105, 5027-5036, 2000.

Litynska, Z., Koepke, P., De Backer, H., Gröbner, J., Schmalwieser, A., and Vuilleumier, L.: Long term changes and climatology of UV radiation over Europe. Final scientific report COST Action 726, available at: http://www-med-physik.vu-wien. ac.at/uv/COST726/COST726_Dateien/Results_Finalreport/ COST726_fnal_report.pdf, 2010.

López, M. L., Palancar, G. G., and Toselli, B. M.: Effect of different types of clouds on surface UV-B and total solar irradiance at southern mid-latitudes: CMF determinations at Córdoba, Argentina, Atmos. Environ., 43, 3130-3136, 2009.

Lubin, D. and Frederick, J. E.: The ultraviolet radiation environment of the Antarctic Peninsula: The roles of ozone and cloud cover,
J. Appl. Meteorol., 30, 478-493, 1991

Lyamani, H., Olmo, F. J., and Alados-Arboledas, L.: Physical and optical properties of aerosols over an urban location in Spain: seasonal and diurnal variability, Atmos. Chem. Phys., 10, 239254, doi:10.5194/acp-10-239-2010, 2010.

Madronich, S.: Analytic formula for the clear-sky UV index, Photochem. Photobiol., 83, 1537-1538, doi:10.1111/j.17511097.2010.00860.x, 2007.

Marshak, A., Knyazikhin, Y., Evans, K. D., and Wiscombe, W. J.: The "RED versus NIR" plane to retrieve broken-cloud optical depth from ground-based measurements, J. Atmos. Sci., 61, 1911-1925, 2004.

McKinlay, A. F. and Diffey, B. L.: A reference spectrum for ultraviolet induced erythema in human skin, CIE J., 6, 21-27, 1987.

Mayer, B. and Kylling, A.: Technical note: The libRadtran software package for radiative transfer calculations - description and examples of use, Atmos. Chem. Phys., 5, 1855-1877, doi:10.5194/acp-5-1855-2005, 2005.

Mayer, B., Seckmeyer, G., and Kylling, A.: Systematic long-term comparison of spectral UV measurements and UVSPEC modelling results, J. Geophys. Res., 102, 8755-8767, 1997.

Mayer, B., Kylling, A., Madronich, S., and Seckmeyer, G.: Enhanced absorption of UV radiation due to multiple scattering in clouds, Experimental evidence and theoretical explanation, J. Geophys. Res., 103, 31241-31254, 1998.

Mateos, D., de Miguel, A., Bilbao, J., and Pérez-Burgos, A.: Dependence of ultraviolet (erythemal and total) radiation and CMF values on total and low cloud covers in Central Spain, Atmos. Res., 98, 21-27, 2010.

Mateos, D., di Sarra, A., Meloni, D., Di Biagio, C., and Sferlazzo, D. M.: Experimental determination of cloud influence on the spectral UV irradiance and implications for biological effects, J. Atmos. Sol.-Terr. Phy., 73, 1739-1746, 2011.

Min, Q. and Harrison, L. C.: Cloud properties derived from surface MFRSR measurements and comparison with GOES results at the ARM SGP site, J. Geophys. Res., 23, 1641-1644, 1996.

Nichol, S. E., Pfister, G., Bodeker, G. E., Mckenzie, R. L., and Wood, S. W.: Moderation of cloud reduction of UV in the Antarctic due to high surface albedo, J. Appl. Meteorol., 42, 1174-1183, 2003.

Paltridge, G. W. and Barton, I. J.: Erythemal ultraviolet radiation distribution over Australia - The calculations, detailed results and input data, Tech. Pap. 33, 48 pp., Aust. Div. of Atmos. Phys., Commonw. Sci. and Indus. Res. Organ., Aspendale, Victoria, Australia, 1978.

Sabburg, J. and Calbó, J.: Five years of cloud enhanced surface UV radiation measurements at two sites (in the Northern and Southern Hemispheres), Atmos. Res., 93, 902-912, 2009.

Sabburg, J. and Wong, J.: Evaluation of sky/cloud formula for estimating UV-B irradiance under cloudy skies, J. Geophys. Res., 105, 29685-29691, 2000.

Schafer, J. S., Saxena, V. K., Wenny, B. N., Barnard, W., and DeLuisi, J. J.: Observed influences of clouds on ultraviolet-B radiation, Geophys. Res. Lett., 23, 2625-2628, 1996.

Schaaf, C. B., Gao, F., Strahler, A. H., Lucht, W., Li, X., Tsang, T., Strugnell, N. C., Zhang, X., Jin, Y., Muller, J. P., Lewis, P., Barnsley, M., Hobson, P., Disney, M., Roberts, G., Dunderdale, M., Doll, C., d'Entremont, R. P., Hug, B., Liang, S., Privette, J. L., and Roy, D.: First operational BRDF, albedo nadir reflectance 
products from MODIS, Remote Sens. Environ., 83, 135-148, 2002.

Schwander, H., Koepke, P., Kaifel, A., and Seckmeyer, G.: Modification of spectral UV irradiance by clouds, J. Geophys. Res., 107, 4296, doi:10.1029/2001JD001297, 2002.

Shettle, E. P.: Models of aerosols, clouds and precipitation for atmospheric propagation studies, in: AGARD Conference Proceedings No. 454, Atmospheric propagation in the uv, visible, ir and $\mathrm{mm}$-region and related system aspects, Advisory Group for Aerospace Research and Development (AGARD), Brussels, Belgium, 1989.

Thiel, S., Steiner, K., and Seidlitz, H. K.: Modification of global erythemally effective irradiance by clouds, Photochem. Photobiol., 65, 969-973, 1997.

Trepte, S. and Winkler, P.: Reconstruction of erythemal UV irradiance and dose at Hohenpeissenberg (1968-2001) considering trends of total ozone, cloudiness and turbidity, Theor. Appl. Climatol., 77, 159-171, 2004.

Turner, D., Vogelmann, A. M., Austin, R. T., Barnard, J. C., Cady, K., Chiu, J. C., Clough, S. A., Flynn, C., Khaiyer, M. M., Lijegren, J., Johnson, K., Lin, B., Long, C., Marshak, A., Matrosov, S. Y., Mcfarlane, S. A., Miller, M., Min, Q., Minnis, P., O'Hirok, W., Wang, Z., and Wiscombe, W.,: Thin liquid water clouds: Their importance and our challenge, B. Am. Meteorol. Soc., 88, 177-190, 2007.
Vilaplana, J. M., Serrano, A., Antón, M., Cancillo, M. L., Parias, M., Gröbner, J., Hulsen, G., Zablocky, G., Díaz, A., and de la Morena, B.: Report of the El Arenosillo/INTA-COST calibration an intercomparison campaign of UVER broadband radiometers, in: "El Arenosillo", Huelva, Spain, August-September 2007, COST Office, ISBN:978-84-692-2640-7, p. 64, 2009.

Wang, P. and Lenoble, J.: Influence of clouds on UV irradiance at ground level and backscattered exittance, Adv. Atmos. Sci., 13, 217-228, 1996.

Webb, A. and Holick, M.: The role of sunlight in the cutaneous production of vitamin D3, Annu. Rev. Nutr., 8, 375-399, 1998.

World Meteorological Organization (WMO): Scientific assessment of ozone depletion: Global ozone research and monitoring project, Technical Report, 52, Geneva, Switzerland, 2010. 